\title{
BEYOND POSTSUBURBIA? MULTIFUNCTIONAL SERVICE AGGLOMERATION IN VIENNA'S URBAN FRINGE
}

\author{
MARCO HELBICH \\ Institute of Geography, University of Heidelberg, Germany. \\ E-mail: marco.helbich@geog.uni-heidelberg.de
}

Received May 2010; accepted April 2011

\begin{abstract}
The surroundings of European cities are becoming ever more complex and sophisticated landscapes. In recent years there has been an ongoing debate about urban fringes that are developing over and beyond the influence of postsuburban processes into decentralised and non-centred urban landscapes. This paper addresses the urgent need to consider polycentric functional service clustering in the urban fringes based on empirical evidence gathered in Vienna, Austria, which served as a case study. A spatial scan statistic is applied to detect local spatial clusters of services and the bivariate $K(d)$-function is used to investigate the spatial interaction between each nucleus. Due to some significant functional clusters, it has been concluded that agglomeration economies are still of prime interest. Furthermore, some significant attraction between the studied clusters is investigated. Overall, the results do not contradict the concept of postsuburbia yet, which is why a paradigm shift must be ruled out.
\end{abstract}

Key words: postsuburbanisation, cluster detection, spatial scan statistic, bivariate $K(d)$-function, Vienna (Austria)

\section{BACKGROUND - FROM SUBURBIA VIA POSTSUBURBIA TO . . . ?}

As the last decades have shown, urban regions are a highly dynamic type of territory subject to constant change due to endogenous and exogenous influences. The impacts of globalisation, information economies, social and demographic changes have given these areas a distinct appearance (Castells 1989; Hall 1993). This realignment towards a postmodern society and urban development (Dear \& Flusty 2002), has resulted in a self-evident restructuring of the spatial organisation of metropolitan areas and their functional dependencies on the core city. Nowadays the dichotomy between rural and urban areas is becoming increasingly blurred and cities have been 'turned inside out'
(Muller 1997, p. 45). Suburban spatial structures are now often a relic of the past. From a theoretical perspective such urban forms cannot adequately be conceptualised within monocentric urban models (Anas et al. 1998; Clark 2002), whereas some density gradients, like population density or land price, decrease uniformly with distance to the core city (Mills 1970). This transformation process has received considerable attention as an empirical issue and from a theoretical point of view in urban geography, regional science, and territorial planning.

Several recent US (e.g. Giuliano \& Small 1991; McMillen \& McDonald 1998; Soja 2000), and European studies (e.g. Blotevogel 1998; Kagermeier et al. 2001; Kloosterman \& Musterd 2001; Helbich \& Leitner 2010), confirm this 
ongoing (primarily economically aligned) evolution from a monocentric into a polycentric urban structure. This means that there are spatially delineated centres composed of large populations and employment opportunities as well as services within the surroundings of the core city (Kloosterman \& Musterd 2001). Additionally, the concept of polycentrism, which will not be taken into account in the following, serves as an integral planning doctrine (Faludi 2002), not limited to a regional scale as discussed below. It is also an essential part of the European spatial development perspective to get a balanced urban system (European Commission 1999).

Consequently, urban theory (Fishman 1987; Garreau 1992; Kling et al. 1995; Soja 2000; Brake 2005), has already incorporated this new urban fabric of metropolitan areas and has sought to deal with this process of maturation, including a functional enrichment of fringes and a spatial reorganisation that benefits suburban landscapes in various facets. Therefore, a terminological tabula rasa of different concepts (Vaughan et al. 2009), for example, postsuburbia (Kling et al. 1995), edge cities (Garreau 1992), in-between-cities (Sieverts 1998), exopolis (Soja 2000), among others, is suggested for dealing with these novel US and European structures. One common feature is fragmented and polynucleated functional patches of services, located within the urban fringes.

In the following, postsuburbia is examined and discussed because it is the most comprehensive concept, under which various current development tendencies such as the agglomeration of offices, retail space in the urban fringes, fragmentation of the metropolitan area, the diversity of the population and multinucleated structure in the surroundings of the core city can be subsumed. Because of this diversity, this study addresses only the latter aspect, namely the multinucleated urban landscape. Lifestyle businesses and health services relocating to the cities' surroundings constitute a rather new and unique development compared to the suburbanisation era. These relocations have resulted in a functional enrichment of the urban fringes, which contrasts with the core idea of Christaller's central place theory (Brake 2005). Because of the increased importance of agglomeration economies and the need to maximise profits, services aspire to spatial proximity and form spatial clusters (Soja 2001). ${ }^{1}$ Bökemann (1999) sees a cluster as an agglomeration of services or institutions in a particular location. The result is a polynucleated functional urban structure in the former suburban fringes. This, in turn, has given way to intra-regional interaction patterns, which become more diffuse and multidirectional (Hesse 2001; Schwanen et al. 2001). Some authors, Kunzmann (2001) and Brake (2005) among others, argue that the functionally enriched polycentric pattern has already resulted in an emancipation of the fringes from the core city. Thus, the traditional core city has lost its primary status, becoming just one of many parts of the metropolitan area (Fishman 1987; Brake 2005). Kunzmann's (2001) archipelago of the metropolitan area summarises this re-shaping process and backs his claim that today's urban fringes consist of several more or less independent monofunctional clusters of firms.

There is an ongoing debate, initiated by Gordon and Richardson (1996) and generalised by Lang (2003), Lang and LeFurgy (2003) as well as Lang et al. (2009), on spatial patterns developing beyond postsuburban polycentric landscapes. According to this concept, postsuburban landscapes are just a transitory phase leading up to a scattered intrametropolitan urban structure (Shearmur et al. 2007), which is conceptualised and refined in Lang's (2003) 'edgeless cities'. This diffuse concept describes a kind of scattered office development throughout the urban landscape which never assumes the scale, density, and cohesiveness of edge cities.

While spatial changes from sub to postsuburbia are theoretically and empirically well known at present (e.g. Fishman 1987; Kling et al. 1995; Soja 2000), there has been less research seeking to find evidence for urban structures beyond these urban patterns (e.g. Lang \& LeFurgy 2003; Phelps et al. 2006; Lang et al. 2009). On this subject, this paper makes an initial empirical contribution and charts current urban patterns. Therefore, first, the paper aims to find local geographic agglomerations of services in the Viennese urban fringe, which would refute the thesis of diffuse urban forms. Second, if some clusters are available, the focus lies on the 
spatial relationship between them, to evaluate possible urban structures beyond Kunzmann's (2001) reference model. More specifically, the following specific research questions are to be addressed. Are there local functional spatial clusters in Vienna's urban fringe? If this can be verified: what are their spatial interrelations? Is there some spatial interaction between their occurrences?

The paper is structured as follows. The following section provides a literature review on empirical manifestations of polycentric and decentralised urban forms. The study area, the data sets, and some data preprocessing steps are then introduced. The subsequent section briefly presents the methodology used to detect local clusters of services and an approach to analysing the relationship between different point patterns. Drawing on the previous section, the results of the empirical analysis are discussed. The paper concludes with a summary, relates the findings to urban theory and discusses the results in comparison to other empirical findings.

\section{EMPIRICAL EVIDENCE OF ALTERED URBAN FORMS}

Urban analysis is a diverse and extensive multidisciplinary field of research (Harris \& Larkham 1999). Little academic considerations deal empirically with European postsuburban structures, the most notable exceptions being Phelps and Parsons (2003), Bontje and Burdack (2005), Phelps et al. (2006) as well as Helbich and Leitner (2009, 2010).

The transformation of metropolitan areas into polycentric urban patterns has been examined primarily in the US (e.g. McMillen 1996), and selected European cities (e.g. Dieleman \& Faludi 1998). At present this is still a novel research topic as there is no common topology and taxonomy concerning the methods and operationalisation of evaluating local spatial variability. One reason is probably the fact that a 'grand theory of polycentricity' is still missing (Kloosterman \& Musterd 2001, p. 624), which complicates the comparison of empirical findings due to the application of different techniques.

For example, Feser and Sweeney (2000) applied a point pattern approach and showed an association between economic linkages and geographic clustering in the US state of North Carolina. Enterprises in knowledge-based or technology-intensive sectors in particular tend to cluster in space. In comparison, Maoh and Kanaroglou (2007) related economic clustering to urban form, using the city of Hamilton, Canada, as a case study. They concluded that a multinucleated urban form is likely to emerge. Finally, Cuthbert and Anderson (2002) demonstrate the strength of point pattern analysis for the Halifax-Dartmouth region in Canada and found evidence for a changing urban form with a tendency towards multinucleation.

Two prime examples of polycentric urban landscapes are the US metropolises of Chicago and Los Angeles. McMillen (1996) stated that Chicago's monocentric pattern already ceased to exist in the 1960s in favour of subcentres, classified as edge cities with multifunctional concentrations of offices, retail, leisure, and housing areas (McMillen \& McDonald 1998). Several other scholars, notably Fishman (1987), Giuliano and Small (1991), Kling et al. (1995), and Soja (2000), agree that the Los Angeles metropolitan area is a prototype for a postsuburban landscape. Beyond that, there is literature on a set of numerous other North American case studies for polycentric structures (e.g. Bogart \& Ferry 1999; Coffey \& Shearmur 2002).

In Europe examples of polycentric urban patterns have been identified in the Dutch Randstad (Dieleman \& Faludi 1998), the Rhine-Ruhr metropolitan region (Blotevogel 1998), Munich (Kagermeier et al. 2001), and Vienna (Helbich \& Leitner 2010), among others. Bontje and Burdack (2005) evaluated the possible occurrence of edge cities in European metropolitan areas, such as Paris and the Dutch Randstad. Because Garreau's (1992) criteria $^{2}$ of an edge city could not be found, they concluded that 'city edges' are the European pendants to the North American edge cities. Nevertheless, city edges have some similarity in terms of specialisation (e.g. financial and insurance institutions), with edge cities, but are not spatially independent of the traditional core city. Also Phelps et al. (2006) emphasise that the postmodernity of US cities can be rarely found to the same degree in the European context; as such their case studies (e.g. 
Noisy-le-Grand next to Paris) are unlike US ones. Moreover, there is heterogeneity within European countries. Helbich and Leitner (2010) undertook the first attempts to quantify postsuburban spatial phenomena for Vienna's urban fringe. Their findings refer to the spatially clustering effects of services. However, since they worked with global clustering tests, their study clearly has methodological limitations. It was not possible to detect local, and thus mappable, clusters. In addition, they did not investigate spatial interaction between services.

Few examples exist that refute the existence of a polycentric urban region in Europe. Baumont et al. (2004) have analysed the spatial distribution of population and employment in the metropolitan area of Dijon (France) and concluded that the spatial pattern still exhibits a monocentric character. Also, Riguelle et al. (2007) claim that for Brussels spatial patterns towards polycentrism are still weak.

Few investigations deal with intrametropolitan scatteration and edgeless cities, respectively. Yet, the results from Gordon and Richardson (1996) suggest that Los Angeles had already matured from a polycentric to a dispersed metropolitan area. Also, Lang (2003) agreed with the notion of Los Angeles being a dispersed metropolitan area. Lang (2003) and Lang et al. (2009) found evidence for such a pattern in Miami and Philadelphia too. In addition, Lee (2007) empirically supports the hypothesis of continuing decentralisation for Portland and Philadelphia. Recently, based on case studies of the Canadian cities of Toronto, Montreal, and Vancouver, Shearmur et al. (2007) found evidence that both concepts, polycentrism and scatteration, occurred simultaneously on different spatial and temporal scales. However, it is still unclear what theoretical implications this will have.

In general, since the results of US cities are only partially valid for European metropolitan areas (Phelps et al. 2006), deeper insights into spatial processes will certainly require more research. This will enable more general conclusions and knowledge as to what extent postsuburban processes shape European urban fringes.

\section{STUDY AREA AND DATA}

Study area - The Vienna urban fringe serves as the study area, where the emergence of postsuburban patterns is, most likely to have occurred within the Austrian context. Since the 1980s this area has been altered by migration from urban to rural areas. Thereby, the population is not homogenously distributed throughout the fringe. Hot spots that are significant in terms of population are located to the north of Vienna and along the main traffic axis in the south (Helbich \& Leitner 2009). This corresponds to the spatial distribution of services that followed after a short time lag. These services completed the facilities in the surroundings (Fassmann et al. 2009). But the designation of protective areas, like the biosphere reserve Wienerwald, in the southwestern parts of the fringe, as well as tight normative planning laws and local regulatory power prevent undesirable developments and uncontrolled settlement growth. Nevertheless, Musil and Pindur (2008) predict stronger urban development pressure in far more peripheral areas for the coming years.

For delimitation purposes a slightly modified outer boundary compared to the one of Fuchs (1997) is used. In the applied definition of the urban fringe, the core city is excluded because the focus lies on polycentric patterns in the surroundings and, in addition, the urban structure outside the traditional core city has already matured, becoming independent, and has (theoretically) broken away from its core (Phelps 2004; Brake 2005). Consequently, the core city has become marginalised, since it is only one of many nuclei of the urban structure (Fishman 1987; Brake 2005). Further, current spatial processes manifest themselves in urban fringes (e.g. Soja 2000). This also holds true for the structure of postsuburban landscapes where service clusters are exclusively located in the surroundings of the core city. However, the specific inner city subcentres are in this case not of interest but still certainly present.

Data and data preprocessing - For this study geo-referenced locations of service sector firms from April 2006 are used to evaluate polynucleated urban structures in the Viennese fringes. The micro-geographic dataset was collected 


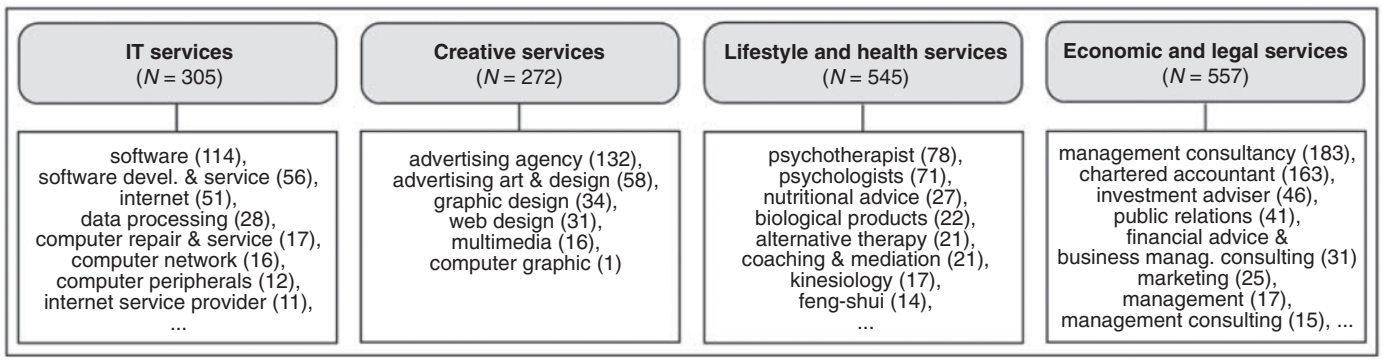

Figure 1. Aggregation of individual economic activities to supergroups.

and sold as 'Marketing CD Business Geo' from the commercial data provider Herold Business Data. It contains highly accurate georeferenced firm locations and associated attributes, as, for instance, the industrial classification code and business volumes.

As mentioned above, it is characteristic of a postsuburban structure, namely, atypical of suburban conditions, that firms are increasingly located in the urban fringes. A larger number of highly specialised firms in the urban fringes results in their functional enrichment and in a growing demographic and socioeconomic diversity of their population. This, in turn, has changed the proportion between supply and demand of goods and services and has attracted new services to the urban fringes (Brake 2005). While these service locations allow a cross-linked production, large-scale industries have lost their importance (Soja 2001; Fassmann 2004). Therefore, this paper focuses on the service sector and its location patterns. From now on these services are referred to as 'postsuburban services'. Due to diverse lineage, development trajectories, and complexity Phelps and Parsons (2003) argue that it is not advisable to apply North American concepts to European settings. Thus, Kunzmann's (2001) less common archipelago of the metropolitan area serves as the base model. In this case it seems appropriate because it is theoretically based on the European metropolitan area of Munich, having almost similar economic, social, and demographic conditions and spatial planning policies compared with Vienna. He argues that today's metropolitan areas have a multinucleated urban pattern and consist of several monofunctional clusters of services. As a next step, based on Kunzmann (2001), the postsuburban services are aggregated to supergroups of postsuburban services. Therefore, the Herold classification code, a classification of economic activities, was used to establish the four postsuburban supergroups (Figure 1).

The resulting spatial distribution, used for further analysis, is visualised in Figure 2. Overall, there are approximately 25,700 services located in the Viennese fringe, about 7 per cent corresponding to one of the four postsuburban services.

\section{METHODOLOGY}

Spatial statistics offers numerous techniques for quantifying spatial point patterns. Global statistics evaluates a point pattern throughout the whole study site. Thus, it is not possible to pinpoint local spatial clusters. Jacquez (2008) noted that local cluster detection methods (e.g. Openshaw et al. 1987; Besag \& Newell 1991; Kulldorff \& Nagarwalla 1995) overcome this shortcoming and they are essential for quantifying geographic patterns, without being affected by the well-known modifiable areal unit problem in spatial analysis (Openshaw 1984). From a statistical point of view a spatial cluster is a spatially bounded group of cases of sufficient size and concentration to be unlikely by chance alone (Knox 1989). In this paper a spatial scan statistic approach is used to detect a polycentric structure of postsuburban services and bivariate $K(d)$-functions are examined to analyse the spatial relationships between the point patterns of postsuburban services in Vienna's urban fringe. 

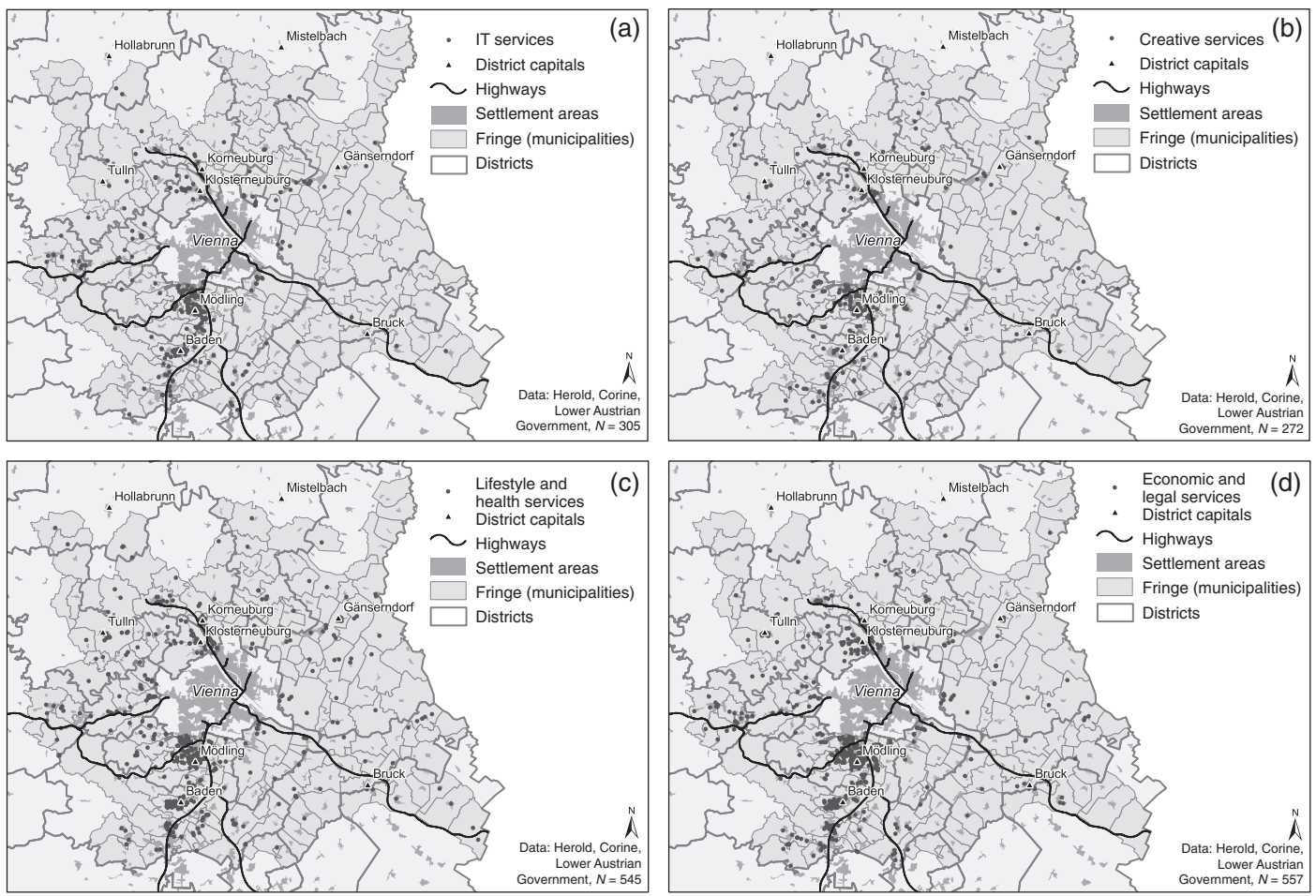

Figure 2. Spatial distribution of the postsuburban services: (a) IT services; (b) creative services; (c) lifestyle and health services; and (d) economic and legal services.

Spatial scan statistic - Spatial scan statistic (SSS; Kulldorff \& Nagarwalla 1995; Kulldorff 1997); is a cutting-edge and reliable local geographical cluster detection methodology. Numerous applications in diverse disciplines have shown the utility and potential of this approach (e.g. Pearl et al. 2006; Leitner \& Helbich forthcoming). Compared to earlier approaches to determine subcentres (e.g. Giuliano \& Small 1991; Bogart \& Ferry 1999), there is no need to set threshold values. On the other hand, limited experience exists in the application on urban geographical analysis (e.g. Montrone et al. 2009; Tuia et al. 2009).

Here, the Bernoulli-based SSS (Kulldorff 1997), is applied to detect polycentric urban forms, meaning that dichotomised data (in the manner of cases and controls) are compared. This approach enables one to take into account heterogeneous distributed background population across space. Thus, the aim is to determine significant local clusters (hot spots) of the cases (services aggregated above) compared to

the heterogeneous distributed control population. The algorithm can be briefly described as follows: A two-dimensional circular scan window moves from case $i$ to case $j$ throughout the study site $R$ and compares the observed cases inside each window according to the null hypothesis with the expected amount of cases. To detect different sizes of clusters the scan window continuously changes its size from zero up to a recommended value of 50 per cent of all cases (Kulldorff 2010), which allows the detection of varying cluster sizes without any pre-selection bias. The reason for scanning up to such a large cluster is the lack of prior knowledge about the true cluster size. For each window the following likelihood function is calculated (Kulldorff 1997):

$$
\begin{aligned}
& \left(\frac{c}{n}\right)^{c}\left(\frac{n-c}{n}\right)^{n-c}\left(\frac{C-c}{N-n}\right)^{C-c} \\
& \left(\frac{(N-n)-(C-c)}{N-n}\right)^{(N-n)-(C-c)} I \mathrm{O}
\end{aligned}
$$


where $c$ are the observed cases inside a scan window, $C$ is the total amount of cases, $n$ is the total amount of cases and controls inside a scan window and $N$ are all cases and controls of the data set. The most likely cluster also called primary cluster, maximises the maximum likelihood ratio statistic. In comparison, secondary clusters are clusters with reduced likelihood values. Monte Carlo hypothesis testing is used to determine significance.

Compared to other methods (e.g. Openshaw et al. 1987; Besag \& Newell 1991), SSS considers multiple hypotheses testing and allows for covariates adjustment. Performance tests have already shown the suitability of SSS, in particular if the cluster size and morphology is not known a priori (Song \& Kulldorff 2003). Kulldorff et al. (2004) have shown that SSS has the ability to detect non-circular clusters (e.g. along a transport axis) as well. Nevertheless, this issue has drawn some criticism. For instance, Tango and Takahashi (2005) argued that a circular window is not appropriate because most geographical clusters do not follow such a circular morphology and promoted their flexibly shaped spatial scan statistic. Finally, Kulldorff et al. (2006) refute this by means of an empirical study and emphasise the additional virtue of this approach.

Bivariate $\boldsymbol{K}(\boldsymbol{d})$-function - A common approach used to quantify the strength and type of the spatial association between different point patterns is to apply the bivariate $K(d)$-function (Ripley 1976). Thus, one is interested in the relative relationship between two point patterns $i$ and $j$. Therefore, it is not necessary to account for spatial heterogeneity as discussed above. Following Dixon (2002), the bivariate $K(d)$-function is defined as:

$K_{i j}=\lambda_{j}^{-1} E[$ number of type $j$ case within a distance $d$ of a randomly chosen type $i$ case]

where $\lambda$ are the points per unit area (Ripley 1976; Dixon 2002). One possible edge corrected estimator commonly used is:

$\hat{K}_{i j}(d)=\left(\hat{\lambda}_{i} \hat{\lambda}_{j} R\right)^{-1} \sum_{k} \sum_{l} w\left(i_{k}, j_{l}\right) I\left(d_{i k, j l}<d\right)$

where $d_{i k, j l}$ is the distance between the $k$ th case of type $i$ and the $l$ th location of type $j, R$ is the area of the study site and $w\left(i_{k}, j_{l}\right)$ accounts for the edge correction. For variance stabilisation and easier interpretation purposes $\hat{K}_{i j}(d)$ will be transformed to (Besag 1977):

$$
\hat{L}_{i j}(d)=\sqrt{\frac{\hat{K}_{i j}(d)}{\pi}}-d
$$

If $\hat{L}_{i j}(d)$ is plotted against a distance $d$, every variation from $\hat{L}_{i j}(d)=0$ can be interpreted as deviation from the null hypothesis of no spatial interaction between the two point patterns $i$ and $j$. Positive values $\hat{L}_{i j}(d)>0$ will present some attraction between the two point patterns at distance $d$, tantamount to both patterns occurring in spatial proximity. Values of $\hat{L}_{i j}(d)<0$ refer to repulsion of the two point patterns at a distance $d$, meaning that both patterns tend to greater distances than expected under the null hypothesis. Inference is again carried out using simulated confidence envelopes (Rowlingson \& Diggle 1993).

\section{EMPIRICAL FINDINGS}

The following section discusses the results of the empirical analysis using the methodology presented above. In general, the selected postsuburban services are heterogeneously distributed over the urban fringe, as seen in Figure 2, and the total number of services for each supergroup located in the fringe is approximately one-fifth compared to those offered in the core city; this emphasises the ongoing importance of the core for the whole metropolis.

In particular, service agglomerations are located in the north of Vienna and along the main traffic axis in the south. The distributions of the four postsuburban services are, not surprisingly, concentrated in and around urban agglomerations, such as Klosterneuburg in the north of Vienna and in the south Baden, Brunn am Gebirge, Wiener Neustadt and Vösendorf, with one of the largest shopping centres in Central Europe located there. Thus, the services are eager to be located near their customers and other firms to profit from spatial proximity and knowledge spillovers. Further postsuburban processes manifest themselves in two recently built business parks in the southern urban 
fringe, namely campus21 (Brunn am Gebirge) and Concorde (Schwechat). Both advertise their outstanding connection to Vienna and the international airport, unique infrastructure (e.g. ready-for-occupancy offices, shops, fitness centre), etc. The former, for instance, also accommodates some global acting companies, like the Austrian corporate headquarters of McDonald's. Without doubt these issues must be interpreted as selective postsuburban developments. Second, normative planning laws determine where certain facilities are allowed to be located and prevent an homogenous distribution. Nevertheless, these subjective interpretations of service clustering require some spatial statistical analysis to formally test for the presence of clusters.

To verify the stated hypotheses of local geographic clusters of postsuburban services in the Viennese urban fringe, resulting in a polycentric urban landscape, SSS was used to scan for areas with a high amount of cases. In addition to cluster detection this method assigns each cluster some likelihood value and allows for inference. Thus, a control point pattern was needed for each point pattern of postsuburban services to adjust for the a priori heterogeneous distributed background population across space. For this purpose, random samples of 20 per cent of all 23,983 service locations in the study area were determined, excluding the four supergroups that were previously selected. Sampling was necessary to keep the computation feasible. For Monte Carlo inference, 9,999 replications were performed. In this study the null hypothesis of no spatial cluster was rejected when the simulated $p$-value was less than 0.05 .

Figure 3 shows the locations of detected clusters for every supergroup, whereas each cluster is labelled with its cluster category on the basis of its significance values. Every pattern has one highly significant primary cluster (C1), mainly located in the south of Vienna, meaning that
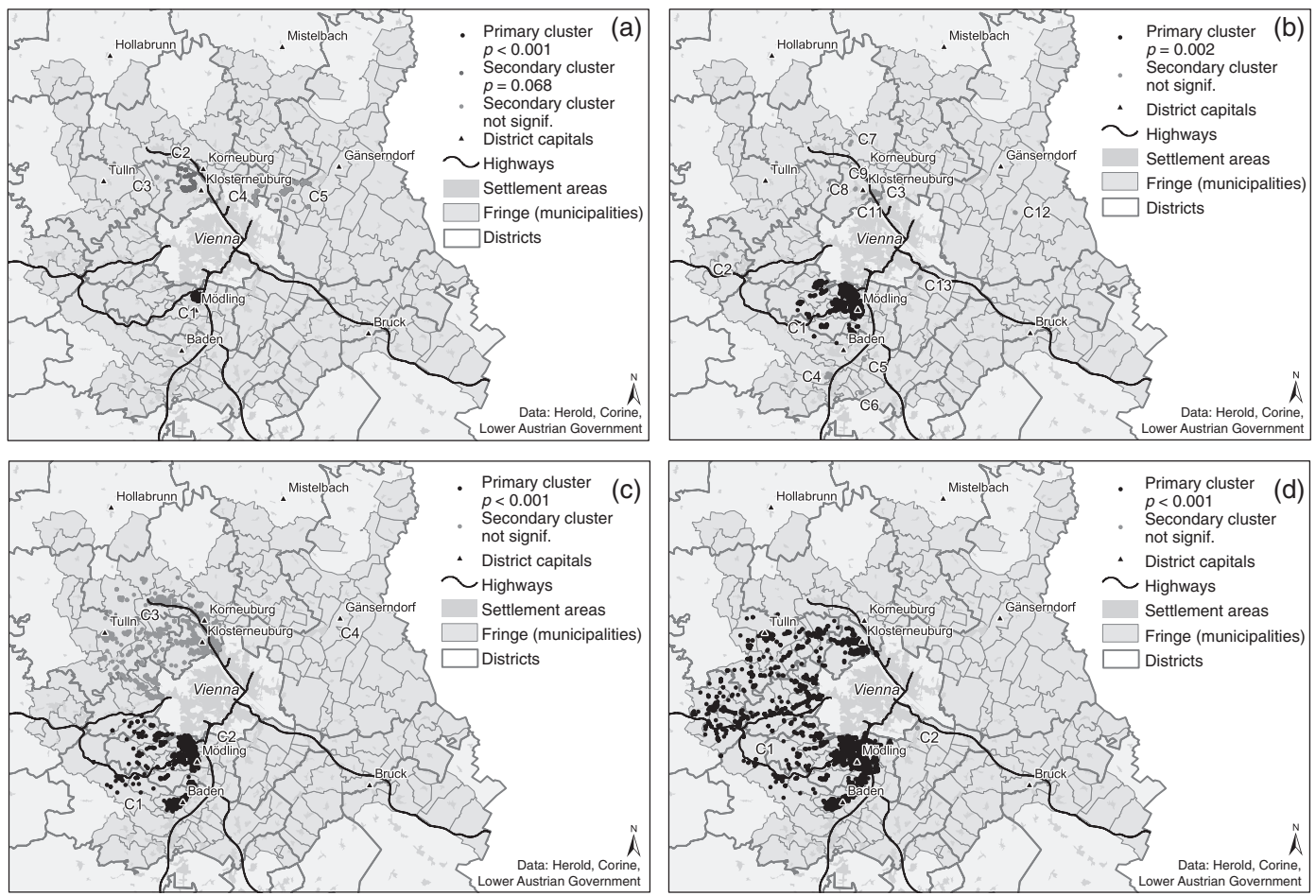

Figure 3. Spatial clusters of the postsuburban services: (a) IT services; (b) creative services; (c) lifestyle and health services; and (d) economic and legal services. 
Table 1. Statistics of the mapped primary clusters (C1).

\begin{tabular}{|c|c|c|c|c|c|}
\hline & $\begin{array}{l}\text { Number } \\
\text { of cases }\end{array}$ & $\begin{array}{l}\text { Expected } \\
\text { cases }\end{array}$ & $\begin{array}{c}\text { Observed } \\
\text { expected ratio }\end{array}$ & $\begin{array}{l}\text { Log likeli- } \\
\text { hood ratio }\end{array}$ & $p$-value \\
\hline IT services & 25 & 5.160 & 4.840 & 22.801 & $<0.001$ \\
\hline Creative services & 71 & 38.740 & 1.830 & 13.942 & $<0.002$ \\
\hline Lifestyle and health services & 168 & 103.950 & 1.620 & 24.186 & $<0.001$ \\
\hline Economic and legal services & 358 & 269.010 & 1.330 & 31.915 & $<0.001$ \\
\hline
\end{tabular}

there are more postsuburban services than other services from the control population. All secondary clusters are not significant at $p<0.05$ (IT services have a $p$-value approximately equal to the critical value, Fig. 3a).

Additionally, Table 1 presents some cluster details and summarises their properties. The considerable differences in the cluster sizes are striking. For instance, the small primary cluster of IT services consists of 25 objects and its counterpart the primary cluster of the economic and legal service supergroup has nearly 15 times more objects. Moreover, Figure 3 refers to some geographical overlap of the postsuburban clusters in the southern area of the urban fringe, which could be a first note on some spatial relationships.

To quantify this possible spatial association between the four point patterns bivariate $K(d)$ functions are applied. To evaluate the spatial relationship, the $\hat{L}_{i j}(d)$-functions are plotted against a distance $\mathrm{d}(\mathrm{m})$ (Figure 4$)$. Significance was again obtained by 499 Monte Carlo simulations. ${ }^{3}$ These simulation runs create critical envelops. Values around $\hat{L}_{i j}(d)=0 \quad$ (null hypothesis) provide a reference for independence of the two spatial processes.

Overall, all four plots show positive deviations from zero, tantamount to spatial attraction. For most distances up to five kilometres the estimated functions are above the confidence envelopes. Thus, the null hypothesis must be rejected. This means that the number of IT services available in the neighbourhood of creative services (or equivalently the number of creative services in the neighbourhood of IT services), is significantly higher than expected. This interpretation is true for all other plots in Figure 4. Beyond a distance of five kilometres the patterns are still attracted to each other but no longer significant up to the analysed distance of 20 kilometres. The comparison between these six bivariate $\hat{L}_{i j}(d)$-functions suggests differences in the strength of the relationships. The strongest attraction is observable between the lifestyle and health services versus the economic and legal services. The final section summarises findings from this research and draws conclusions and further implications for the theoretical discourse.

\section{DISCUSSION}

Today metropolitan areas are facing pervasive changes of their urban spatial structure and are reshaped by spatial processes. This paper examined the spatial structure of the Viennese urban fringe as a case study based on the distribution of specific services. On the one hand, local spatial clusters are investigated and on the other hand, their spatial interrelations are quantified applying spatial statistics.

First it analysed the current spatial formation of services and addressed the question, whether there are multinucleated monofunctional clusters of higher-order services, which can be interpreted as a polycentric pattern. This state would be a characteristic of postsuburban development processes (Kunzmann 2001; Brake 2005). On this basis, the second part examined these postsuburban clusters to see whether they have already become some new urban landscape and evaluated the spatial relationship between the detected monofunctional service clusters. Hence, this study follows Lang et al. (2009) who investigated US metropolises, to see if the observable spatial patterns of offices are already beyond edge cities and thus consequently beyond postsuburbanisation processes. The first section argues that the cited terms such as edge city, postsuburbia or exopolis highlight a maturity process (e.g. functional 
IT services vs. Creative services

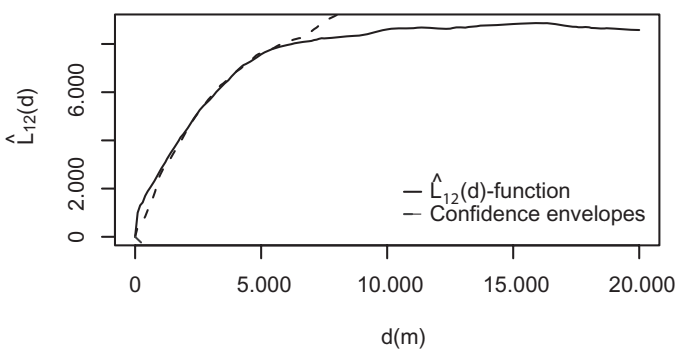

IT services vs. Economic services

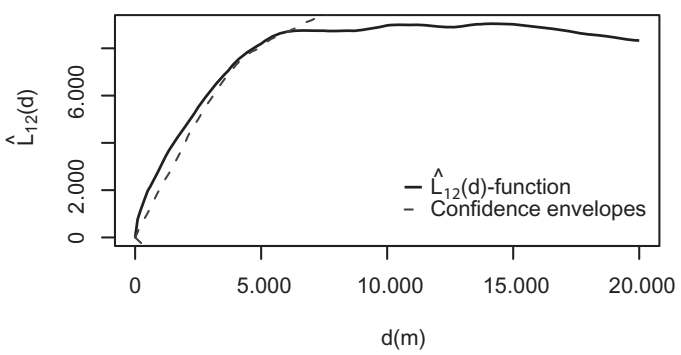

Creative services vs. Economic services

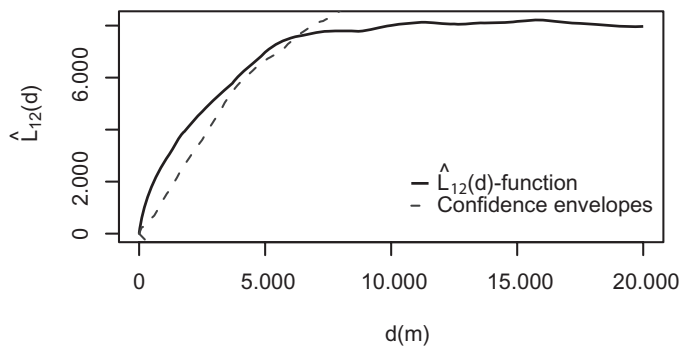

IT services vs. Lifestyle services

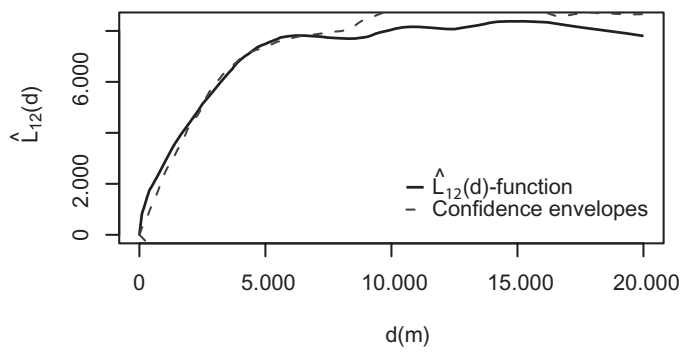

Creative services vs. Lifestyle services

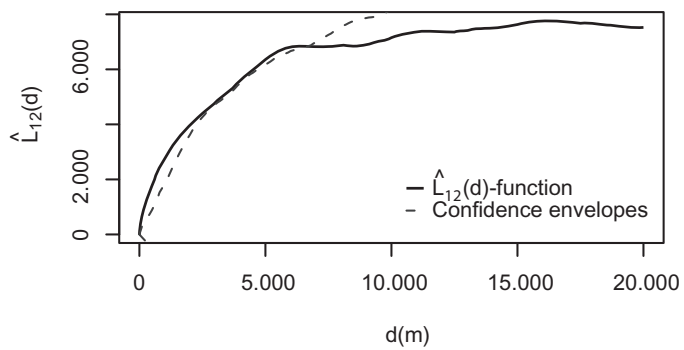

Lifestyle services vs. Economic services

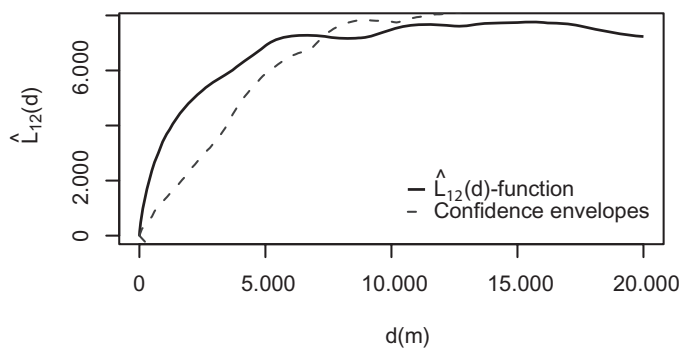

Figure 4. Estimated bivariate $\hat{L}_{i j}(d)$-functions of the postsuburban services. Dashed lines represent the simulated confidence envelopes and solid lines represent the empirical functions (headings are abbreviated).

enrichment of services, spatial reorganisation) of the urban landscapes referring to a postmodern society (Dear \& Flusty 2002). The methodological framework uses micro-geographic data of service locations for the year 2006 and spatial statistics, namely the spatial scan statistic and the bivariate $K(d)$-function, to answer these research questions.

The findings show that the urban fringe of Vienna consists of a polycentric urban structure. All results indicate significant functional clusters because analysed services are clearly more clustered than other services in the surroundings. In detail, every point pattern has one highly significant primary cluster, mostly situated in the southern part of the core city, whereas the cluster sizes vary. Most of the primary clusters (e.g. creative services), have a spatial range extending over several administrative units, thus allowing us to conclude that there are no specific locational policies. Compared with another study, the detected clusters are mainly located in traditional suburban areas and reshaping them, as comprehensively analysed in Fassmann et al. (2009). Thus, the cluster locations offer high accessibility to Vienna. The results are consistent with those of Eisenreich and Schenk (2002) for the German Filderregion next to Stuttgart and 
those of Kagermeier et al. (2001) for the metropolitan area of Munich. These new clusters have developed out of existing clusters and have not yet created new economic centres. This leads to the conclusion that there are specific locational qualities in these cluster locations. From an economic geography point of view this means that space still matters and, following Malmberg and Maskell (2002), density can boost localised learning and the innovation process. In particular, agglomeration economies like face-to-face contacts and the creation, exchange, and the diffusion of ideas and knowledge are essential in such economies (Storper \& Venables 2004). By contrast, telecommunication technologies still lack the ability to soften traditional agglomeration economics (Coffey \& Shearmur 2002). Using above point pattern methodology, this study generally does not allow serious statements about the relationship between the core city and the fringe and, specifically, no conclusions can be drawn about the importance of the core city. Therefore, spatiotemporal interaction studies are still required.

Summing up, the hypothesis of monofunctional service agglomerations can be verified by reference to a postsuburban spatial organisation of the Viennese urban fringe. Further, these findings converge with Burdack and Herfert (1998) and Phelps et al. (2006) in their claim that future European metropolitan areas will be characterised by a polycentric urban structure and disconfirm some evolutionary development towards a diffuse urban fabric as proposed by Gordon and Richardson (1996) and Lang (2003).

The second part addressed the spatial relationship between these monofunctional clusters and evaluated the hypothesis of urban structures beyond postsuburbia. Applying several bivariate $K(d)$-functions, the study provided evidence for spatial interaction between their occurrences and are not independent of each other. Thus, clusters aspire spatial proximity next to clusters of another category. With regard to postsuburban processes this is hitherto not known for European fringes. This fact is not accounted for in Kunzmann's (2001) archipelago, which categorically excludes interaction effects, using crisp cluster delimitations. More appropriate would be 'conglomerates of clusters of postsuburban services'. Those are more suitable for the Viennese case as well. Finally, it should be mentioned that the cluster detection algorithm used generates per se crisp instead of fuzzy cluster demarcations, which does not correspond to most real-world phenomena as stated in Leung (1987). A constraint worth mentioning in this study are the sampling procedures, inducing some selection bias. Nevertheless, a further development is assessed, which deviates from our base model, the archipelago of the metropolitan area. Compared to Kunzmann (2001), this partial result rejects the thesis of specific European postsuburban landscape styles and resembles their North American counterparts of mixed service clusters. Proposing a paradigm shift for the Viennese surroundings from a postsuburban development to something new beyond postsuburbia would currently be premature.

Future research is needed to see whether the findings reported here are robust across a wider range of metropolitan areas. Such studies could address the spatial and spatiotemporal development of service clusters, their morphological morphing, and how the centres and their specialisation evolve over time. In addition, comparative studies with other European metropolitan areas are of great theoretical and practical importance to find out whether the results from Vienna are unique or can be generalised to other metropolitan areas. It is hoped that this study will stimulate further investigation in this field. Possibly further work along this line will be fruitful.

\section{Acknowledgements}

I acknowledge the valuable feedback I have received from Alois Humer and Peter Görgl on successive drafts of this paper. In addition, I want to thank Alexander Zipf for helping me obtain the postdoctoral position at the University of Heidelberg, making it possible to prepare this publication. Further, I would also like to acknowledge the constructive comments and feedback from the reviewers. Finally, I want to dedicate this paper to Daniela for her never-ending patience.

\section{Notes}

1. Current research suggests that Marshallian's theory of agglomeration may be insufficient for explaining polycentric urban forms and that 
polycentricity is 'not simply a matter of agglomeration economies producing agglomeration' (Krugman 1996, p. 88 cited in Phelps 2004, p. 978). For a detailed discussion see Phelps and Ozawa (2003) and Phelps (2004).

2. After Garreau (1992) an edge city consists of $450,000 \mathrm{~m}^{2}$ office space, $55,000 \mathrm{~m}^{2}$ retail space, and 24,000 employees.

3. The 499 runs used are a moderate number of simulations, but reduce computation time considerably. I therefore advise the reader to interpret the results, especially the significant ones, with some caution.

\section{REFERENCES}

Anas, A., R. Arnott \& K. Small (1998), Urban Spatial Structure. Journal of Economic Literature 36, pp. 1426-1464.

Baumont, C., C. Ertur \& J. Le Gallo (2004), Spatial Analysis of Employment and Population Density: The Case of the Agglomeration of Dijon. Geographical Analysis 36, pp. 146-176.

BEsaG, J. (1977), Contribution to the Discussion of Dr. Ripley's Paper. Journal of the Royal Statistical Society B 39, pp. 193-195.

Besag, J. \& J. Newell (1991), The Detection of Clusters in Rare Diseases. Journal of the Royal Statistical Society A 154, pp. 143-155.

Blotevogel, H. (1998), The Rhine-Ruhr Metropolitan Region: Reality and Discourse. European Planning Studies 6, pp. 395-410.

BöKemann, D. (1999), Theorie der Raumplanung: Regionalwissenschaftiche Grundlagen für die Stadt-, Regional- und Landesplanung. München: Oldenbourg Verlag.

Bogart, W. \& W. Ferry (1999), Employment Centres in Greater Cleveland: Evidence of Evolution in a Formerly Monocentric City. Urban Studies 36, pp. 2099-2110.

Bontje, M. \& J. Burdack (2005), Edge Cities, European-style: Examples from Paris and the Randstad. Cities 22, pp. 317-330.

Brake, K. (2005), Der Suburbane Raum als Standorttyp. In: K. Brake, I. Einacker \& H. Mäding, eds., Kräfte, Prozesse, Akteure - zur Empirie der Zwischenstadt. Zwischenstadt Band 3, pp. 9-65. Wuppertal: Müller + Busmann.

Burdack, J. \& G. Herfert (1998), Neue Entwicklungen an der Peripherie europäischer Großstädte. Ein Überblick. Europa Regional 6, pp. 26-44.
Castells, M. (1989), Information Technology, Economic Restructuring, and the Urban-Regional Process. Oxford: Blackwell.

Clark, W. (2002), Monocentric to Polycentric: New Urban Forms and Old Paradigms. In: G. BRIDGE \& S. Watson, eds., Companion to the City, pp. 141-154. Oxford: Blackwell.

Coffey, W. \& R. Shearmur (2002), Agglomeration and Dispersion of High-order Service Employment in the Montreal Metropolitan Region, 1981-96. Urban Studies 39, pp. 359-378.

Cuthbert, A. \& W. Anderson (2002), Using Spatial Statistics to Examine the Pattern of Urban Land Development in Halifax-Dartmouth. The Professional Geographer 54, pp. 521-532.

Dear, M. \& S. Flusty (2002), The Resistible Rise of the L.A. School. In: M. Dear, eds., From Chicago to L.A. Making Sense of Urban Theory, pp. 6-16. Thousand Oaks, CA: Sage Publications.

Dieleman, F. \& A. Faludi (1998), Polynucleated Urban Regions in Europe: Theme of the Special Issue. European Planning Studies 6, pp. 365-378.

Dixon, P. (2002), Ripley's K Function. In: A. El-Shaarawi \& W. Piegorsch, eds., Encyclopedia of Environmetrics, 3, pp. 1796-1803. Chichester: Wiley.

Eisenreich, D. \& W. Schenk (2002), Abkopplungstendenzen des suburbanen Raums von der Kernstadt - das Beispiel der Filderregion südlich von Stuttgart. Standort - Zeitschrift für Angewandte Geographie 26, pp. 173-179.

European CoMmission (1999), ESDP - European Spatial Development Perspective. Towards Balanced and Sustainable Development of the Territory of the European Union. Luxembourg: Office for Official Publications of the European Communities.

Faludi, A. (2002), European spatial planning. Cambridge: Lincoln Institute of Land Policy.

Fassmann, H. (2004), Stadtgeographie 1. Braunschweig: Westermann.

Fassmann, H., P. Görgl \& M. Helbich (2009), Atlas der Wachsenden Stadtregion. PGO: Wien.

Feser, E. \& S. SweEney (2000), A Test for the Coincident Economic and Spatial Clustering of Business Enterprises. Journal of Geographical Systems 2, pp. 349-373.

Fishman, R. (1987), Bourgeois Utopias. The Rise and Fall of Suburbia. New York: Basic Books.

Fuchs, I. (1997), Stadtregionen 1991 - das Konzept. Statistische Nachrichten 2, pp. 76-83. 
Garreau, J. (1992), Edge City: Life on the New Frontier. New York: Anchor Books.

Giuliano, G. \& K. Small (1991), Subcenters in the Los Angeles Region. Regional Science and Urban Economics 21, pp. 163-182.

Gordon, P. \& H. Richardson (1996), Beyond Polycentricity: The Dispersed Metropolis, Los Angeles, 1970-1990. Journal of the American Planning Association 62, pp. 289-295.

Hall, P. (1993), Forces Shaping Urban Europe. Urban Studies 30, pp. 883-898.

Harris, R. \& P. LARKham (1999), Changing Suburbs: Foundation, Form and Function. London: E \& FN Spon.

Helbich, M. \& M. Leitner (2009), Spatial Analysis of the Urban-to-rural Migration Determinants in the Viennese Metropolitan Area. A Transition from Suburbia to Postsuburbia? Applied Spatial Analysis and Policy 2, pp. 237-261.

Helbich, M. \& M. Leiter (2010), Postsuburban Spatial Evolution of Vienna's Urban Fringe: Evidence from Point Process Modeling. Urban Geography 31, pp. 1100-1117.

Hesse, M. (2001), Mobilität und Verkehr in (Post-) Suburbia - ein Ausblick. RaumPlanung 95, pp. 65-69.

Jacquez, G.M. (2008), Spatial Cluster Analysis. In: S. Fotheringham \& J. Wilson, eds., The Handbook of Geographic Information Science, pp. 395-416. Malden, MA: Blackwell Publishing.

Kagermeier, A., M. Miosga \& K. Schussmann (2001), Die Region München - Auf dem Weg zu regionalen Patchworkstrukturen. In: K. BRAKE, J. Dangschat \& G. Herfert, eds., Suburbanisierung in Deutschland. Aktuelle Tendenzen, pp. 163-173. Opladen: Leske + Budrich.

Kling, R., S. Olin \& M. Poster (1995), The Emergence of Postsuburbia: An Introduction. In: R. Kling, S. Olin \& M. Poster, eds., Postsuburban California. The Transformation of Orange County since World War II, pp. 1-30. Berkley, CA: University of California Press.

Kloosterman, R. \& S. Musterd (2001), The Polycentric Urban Region: Towards a Research Agenda. Urban Studies 38, pp. 623-633.

Knox, E.G. (1989), Detection of Clusters. In: P. Elliott, ed., Methodology of Enquiries Into Disease Clustering, pp. 17-20. London: Small Area Health Statistics Unit.

KulldorfF, M. (1997), A Spatial Scan Statistic. Communications in Statistics: Theory and Methods 26, pp. 1481-1496.
KulldorfF, M. (2010), SaTScanTM User Guide for version 9.0. Available at <http://www.satscan. $\operatorname{org} />$.

KulldorfF, M. \& N. Nagarwalla (1995), Spatial Disease Clusters: Detection and Inference. Statistics in Medicine 14, pp. 799-810.

Kulldorff, M., Z. Zhang, J. Hartman, R. Heffernan, L. Huang \& F. Mostashari (2004), Evaluating Disease Outbreak Detection Methods: Benchmark Data and Power Calculations. Morbidity and Mortality Weekly Report 53, pp. 144-151.

Kulldorff, M., L. Huang, L. Pickle \& L. Duczmal (2006), An Elliptic Spatial Scan Statistic. Statistics in Medicine 25, 3929-3943.

Kunzmann, K. (2001), Welche Zukünfte für Suburbia? Acht Inseln im Archipel der Stadtregion. In: K. Brake, J. Dangschat \& G. Herfert, eds., Suburbanisierung in Deutschland. Aktuelle Tendenzen, pp. 213-221. Opladen: Leske + Budrich.

LANG, R. (2003), Edgeless Cities: Exploring the Elusive Metropolis. Washington, DC: Brookings Institution Press.

LAng, R. \& J. LeFurgy (2003), Edgeless Cities: Examining the Non-centred Metropolis. Housing Policy Debate 14, pp 427-460.

LAng, R., T.W. SAnchez \& A.C. Oner (2009), Beyond Edge City: Office Geography in the New Metropolis. Urban Geography 30, pp. 726-755.

LeE, B. (2007), 'Edge' or 'Edgeless' Cities? Urban Spatial Structure in U.S. Metropolitan Areas, 1980 to 2000. Journal of Regional Science 47, pp. 479-515.

Leitner, M. \& M. Helbich (forthcoming), The Impact of Hurricanes on Crime: A Spatio-temporal Analysis in the City of Houston, TX. Cartography and Geographic Information Science 37.

LEUNG, Y. (1987), On the Imprecision of Boundaries. Geographical Analysis 19, pp. 125-151.

Malmberg, A. \& P. Maskell (2002), The Elusive Concept of Localization Economies: Towards a Knowledge-based Theory of Spatial Clustering. Environment and Planning A 34, pp. 429-449.

Maoh, H. \& P. Kanaroglou (2007), Geographic Clustering of Firms and Urban Form: A Multivariate Analysis. Journal of Geographical Systems 9, pp. 29-52.

McMillen, D. (1996), One Hundred Fifty Years of Land Values in Chicago: A Nonparametric Approach. Journal of Urban Economics 40, pp. 100124.

McMillen, D. \& J. McDonald (1998), Suburban Subcenters and Employment Density in Metro- 
politan Chicago. Journal of Urban Economics 43, pp. 157-180.

Mills, E.S. (1970), Urban density functions. Urban Studies 7, pp. 5-20.

Montrone, S., P. Perchinunno, A. Di Giuro, F. Rotondo \& C.M. Torre (2009), Identification of 'Hot Spots' of Social and Housing Difficulty in Urban Areas: Scan Statistics for Housing Market and Urban Planning Policies. In: B. Murgante, G. Borruso, A. Lapucci, eds., Geocomputation $\mathcal{E}^{\circ}$ Urban Planning, Studies in Computational Intelligence, Volume 176, pp. 57-78. Berlin: Springer.

Muller, P. (1997), The Suburban Transformation of the Globalizing American City. Annals of the American Academy of Political and Social Science 551, pp. 44-58.

Musil, R. \& P. Pindur (2008), Nachhaltig trotz suburbanen Nutzungsdrucks? Siedlungsentwicklung im Biosphärenpark Wienerwald. Mitteilungen der Österreichischen Geographischen Gesellschaft 150, pp. 121-145.

Openshaw, S. (1984), Modifiable Areal Unit Problem. Norwich: GeoBooks.

Openshaw, S., M. Charlton, C. Wymer \& A.W. Craft (1987), A Mark 1 Analysis Machine for the Automated Analysis of Point Data Sets. International Journal of Geographical Information Systems 1, pp. 335-358.

Pearl, D.L., M. Louie, L. Chui, K. Doré, K.M. GrimSRud, D. Leedell, S.W. Martin, P. Michel, L.W. Svenson \& S.A. McEwen (2006), The Use of Outbreak Information in the Interpretation of Clustering of Reported Cases of Escherichia Coli O157 in Space and Time in Alberta, Canada, 2000-2002. Epidemiology and Infection 134, pp. 699-711.

Phelps, N. (2004), Clusters, Dispersion and the Spaces in Between: For an Economic Geography of the Banal. Urban Studies 41, pp. 971-989.

Phelps, N. \& T. Ozawa (2003), Contrasts in Agglomeration: Proto-industrial, Industrial and Post-industrial Forms Compared. Progress in Human Geography 27, pp. 583-604.

Phelps, N. \& N. Parsons (2003), Edge Urban Geographies: Notes from the Margins of Europe's Capital Cities. Urban Studies 40, pp. 1725-1749.

Phelps, N., N. Parsons, D. Ballas, A. Dowling (2006), Post-suburban Europe. Planning and Politics at the Margins of Europe's Capital Cities. New York: Palgrave Macmillan.
Riguelle, F., I. Thomas \& A. Verhetsel (2007), Measuring Urban Polycentrism: A European Case Study and its Implications. Journal of Economic Geography 7, pp. 193-215.

Ripley, B. (1976), The Second-order Analysis of Stationary Point Processes. Journal of Applied Probability 13, pp. 255-266.

Rowlingson, B. \& P. Diggle (1993), SPLANCS: Spatial Point Pattern Analysis Code in S-Plus. Computers and Geosciences 19, pp. 627-655.

Schwanen, T., M. Frans, F. Dieleman \& M. Dijst (2001), Travel Behaviour in Dutch Monocentric and Policentric Urban Systems. Journal of Transport Geography 9, pp. 173-186.

Shearmur, R., W. Coffey, C. Dubé \& R. Barbonne (2007), Intrametropolitan Employment Structure: Polycentricity, Scatteration, Dispersal and Chaos in Toronto, Montreal and Vancouver, 1996-2001. Urban Studies 44, pp. 1713-1738.

Sieverts, T. (1998), Zwischenstadt. Zwischen Ort und Welt, Raum und Zeit, Stadt und Land. Braunschweig: Vieweg.

Soja, E. (2000), Postmetropolis. Critical Studies of Cities and Regions. Oxford: Blackwell.

Soja, E. (2001), Exploring the Postmetropolis. In: C. Minca, ed., Postmodern Geography: Theory and Praxis, pp. 37-56. Oxford: Blackwell.

Song, C. \& M. KulldorfF (2003), Power Evaluation of Disease Clustering Tests. International Journal of Health Geographics 2, 9.

Storper, M. \& A. Venables (2004), Buzz: Face-toface Contact and the Urban Economy. Journal of Economic Geography 4, pp. 351-370.

TAngo, T. \& K. TAkAhashi (2005), A Flexibly Shaped Spatial Scan Statistic for Detecting Clusters. International Journal of Health Geographics 4, 4-11.

Tuia, D., C. Kaiser, A. Da Cunha \& M. Kanevski (2009), Detection of Urban Socio-economic Patterns Using Clustering Techniques. In: B. Murgante, G. Borruso, A. Lapucci, eds., Geocomputation $\mathcal{E}^{2}$ Urban Planning, Studies in Computational Intelligence, Volume 176, pp. 19-36. Berlin: Springer.

Vaughan, L., S. Griffiths, M. Haklay \& C. Jones (2009), Do the suburbs exist? Discovering Complexity and Specificity in Suburban Built Form. Transactions of the Institute of British Geographers 34, pp. $475-488$. 